\title{
Erro médico - o laudo pericial e a decisão judicial
}

\section{Malpractice - the expert report and the judicial decision}

\author{
Camila Lúcia Dedivitis Tiossi Wild ${ }^{1}$
}

\begin{abstract}
Wild CLDT. Erro médico - o laudo pericial e a decisão judicial. Saúde, Ética \& Justiça. 2014;19(1);21-25.
RESUMO: Considera-se como erro médico toda e qualquer falha ocorrida durante a prestação da assistência à saúde que tenha causado algum tipo de dano ao paciente. O objetivo do trabalho foi avaliar perícias médicas judiciais em erro médico, correlacionar o laudo pericial e sua influência na decisão judicial. Analisamos 30 perícias realizadas no Instituto de Medicina Social e Criminologia do Estado de São Paulo (IMESC) entre janeiro e abril de 2010. O estudo foi realizado em janeiro de 2013. O laudo pericial conseguiu determinar relação de nexo causal entre o atendimento médico e o dano ao periciando em 8 casos, sendo constatada alguma irregularidade no ato médico (mau atendimento médico). Treze processos já haviam sido julgados em $1^{\mathrm{a}}$ instância, sendo 10 considerados improcedentes. O laudo pericial foi acatado pelo juiz em $85 \%$ (11 casos) das decisões judiciais, mostrando que na maioria dos casos é ele que norteia o julgamento.
\end{abstract}

DESCRITORES: Erro Médico; Decisão Judicial.

1. Instituto de Medicina Social e Criminologia do Estado de São Paulo - IMESC.

Endereço de correspondência: Rua Barra Funda, 824 - Barra Funda - São Paulo-SP - CEP: 01152-000. E-mail: camilatiossi@ uol.com.br 


\section{INTRODUÇÃO}

A expressão "erro médico" é por vezes empregada para designar qualquer falha cometida na prestação dos serviços de saúde que tenha ocasionado um dano ao paciente ${ }^{1}$. Em meio aos avanços da ciência e também dos problemas do sistema de saúde do país, estabelecer uma relação próxima entre o médico e o paciente é um dos grandes desafios da medicina moderna. Pode-se conceituar a relação médico-paciente ideal como uma relação de natureza profissional, de confiabilidade recíproca, de honestidade, de direito e deveres do médico e do doente e imbuída de humanismo e compaixão com aquele que está sofrendo.

Considera-se como "erro médico", em sentido amplo, toda e qualquer falha ocorrida durante a prestação da assistência à saúde que tenha causado algum tipo de dano ao paciente ${ }^{1}$. Assim, se o dano tiver como causa a falha de um determinado aparelho na realização de um exame, a indisponibilidade de um leito em UTI, ou mesmo o erro de outros profissionais da saúde (enfermeiros, técnicos etc..) será considerado erro médico.

Legalmente, o erro médico consiste no ato ilícito praticado por profissional habilitado na área que leva a um dano ao paciente por negligência, imprudência ou imperícia ${ }^{2,3}$. Desse modo, o presente trabalho avaliou os processos em que havia alegação de "erro médico", analisando a existência de nexo causal no laudo pericial e sua possível correlação com a decisão judicial.

\section{MATERIAL E MÉTODOS}

Realizou-se a análise retrospectiva de 30 perícias médicas feitas por um mesmo perito no IMESC no período de janeiro a abril de 2010, não havendo exclusão de qualquer processo avaliado no referido período. O levantamento foi realizado em janeiro de 2013 e foram analisados: a conclusão do laudo pericial (má ou boa prática médica), a decisão judicial em $1^{\mathrm{a}}$ instância, o tipo de perícia (indireta ou direta), idade e sexo do periciando.

\section{RESULTADO}

Foram analisadas 30 perícias médicas realizadas entre janeiro e abril de 2010. A idade dos periciandos variou de 0 a 75 anos, tendo uma média de 30,3 anos. Não houve diferença entre a distribuição pelo sexo, sendo encontrados 15 periciandos do sexo masculino e 15 periciandos do sexo feminino.

A maioria das perícias avaliadas foi do tipo indireta (28 pericias). O laudo pericial conseguiu determinar relação de nexo causal entre o atendimento médico e o dano ao periciando em 8 casos (Gráfico 1).
Nessas perícias, constatou-se alguma irregularidade no ato médico que caracterizava negligência, imprudência ou imperícia (mau atendimento médico).

Gráfico 1 - Laudo pericial e determinação de nexo causal

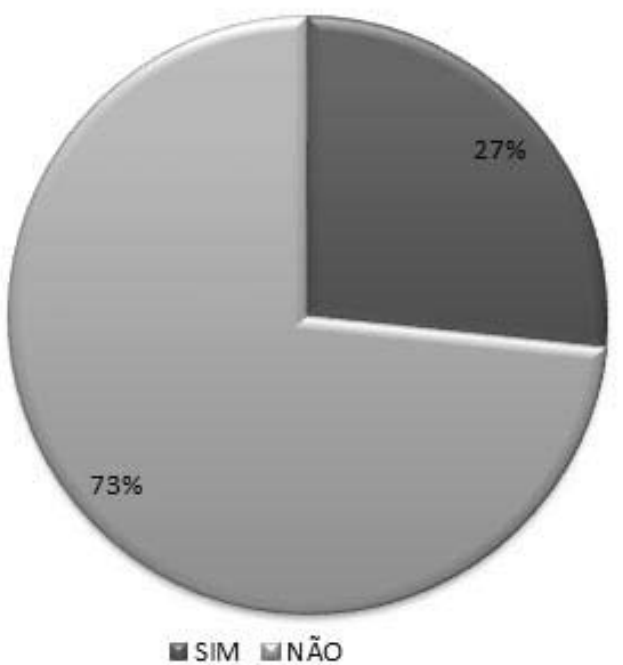

A maioria das perícias realizadas ainda não tinha determinado decisão judicial em $1^{\text {a }}$ instância (sentença). Treze processos já haviam sido julgados em $1^{\mathrm{a}}$ instância, sendo 10 considerados improcedentes (Gráfico 2).

A maioria das decisões judiciais emitidas (11) encontrava-se de acordo com o laudo pericial (Gráfico $3)$.

Uma sentença foi contrária ao laudo pericial. Este expunha elementos de má conduta médica por ter sido dada alta à pericianda sem reavaliação médica descrita em prontuário. A mesma retornou ao hospital após algumas horas em insuficiência respiratória sendo encaminhada para UTI e vindo a falecer no mesmo dia da alta. O médico envolvido alegou, em declaração posterior, que a pericianda havia sido avaliada antes da alta e apresentava boas condições clínicas. Devido à dúvida gerada e ao atendimento médico adequado na UTI, o magistrado acatou como improcedente a ação. A pericianda tinha 2 anos de idade.

Uma sentença foi procedente, sendo contrária ao laudo pericial que determinava boa conduta médica. Nesse caso, a pericianda de 7 anos de idade foi a óbito por causa indeterminada. Apresentou crises convulsivas após administração de plasil em dose adequada. Realizadas medidas pertinentes ao caso. Magistrado entendeu que a equipe médica deveria prever tal reação e evitar a medicação.

Foram respondidos quesitos complementares (QC) em 16 perícias (Gráfico 4). Os quesitos complementares foram requisitados pelas partes para esclarecimentos sobre o laudo pericial. 
Wild CLDT. Erro médico - o laudo pericial e a decisão judicial.

Gráfico 2 - Decisão judicial 1a Instância

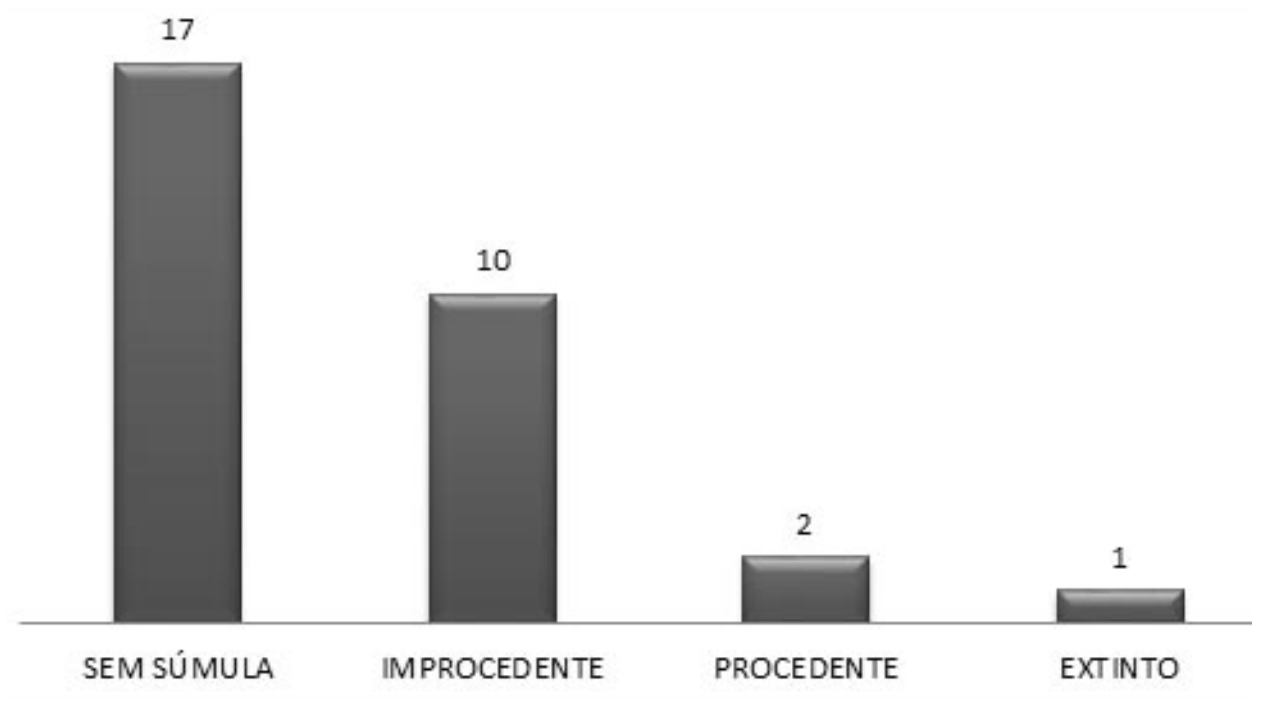

Gráfico 3 - Decisão judicial x Laudo pericial

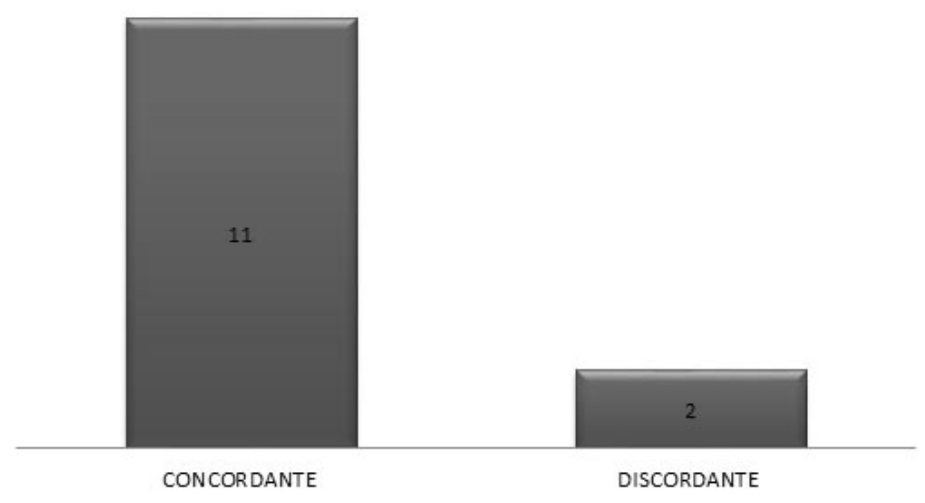

Gráfico 4 - Realização de quesitos complementeares

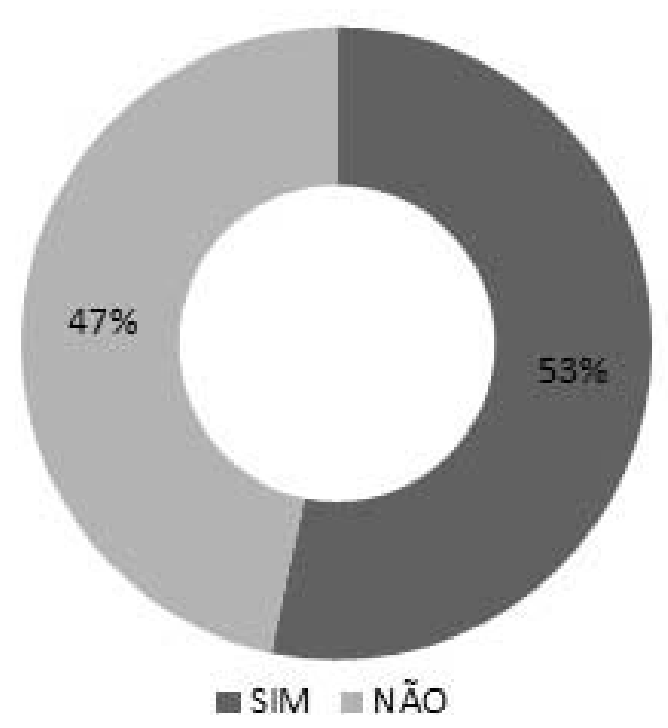




\section{DISCUSSÃO}

A relação entre o médico e o paciente é fundamental para o sucesso de um tratamento. Essa relação pode contribuir muito para evitar danos decorrentes dos chamados "erros médicos" ou de outros problemas ${ }^{1,2,3}$. Uma boa relação médico-paciente depende de algumas medidas simples, como transparência e informação, de parte dos médicos e dos pacientes. O médico, apesar das más condições de trabalho, deve prestar atendimento adequado e humanizado. E o paciente, por sua vez, deve prestar todas as informações necessárias para ajudar o médico no diagnóstico e não pode também deixar de esclarecer todas as dúvidas sobre seu estado de saúde ${ }^{1}$. "Erro médico" é um assunto delicado para o paciente, para o médico e também para outros profissionais de saúde.

Existem situações em que o resultado não é satisfatório para o paciente, mas que não se está diante de erro médico. O resultado adverso, por exemplo, não decorre da má prática médica. Ele acontece quando o profissional, apesar de ter empregado todos os recursos adequados, obtém resultado diferente do pretendido. A adversidade decorre de uma situação incontrolável, própria da evolução do caso ou quando não é possível para a ciência e para a Medicina prever quais pessoas, em quais situações, terão esse resultado indesejado. Outro acontecimento que não deve ser confundido com a má prática médica é o aparecimento de novo fenômeno no curso do tratamento, a exemplo de uma nova doença que agrava o quadro clínico. $\mathrm{Na}$ linguagem médica esse acontecimento é chamado de complicação. Um dos exemplos mais comuns é a infecção hospitalar, que independe da competência médica e ocorre mesmo nos hospitais de melhor qualidade ${ }^{3}$. Nem todo mau resultado de um tratamento médico decorre da má conduta do profissional médico.

A má prática médica pode gerar responsabilidade civil, penal e administrativa.

No campo do direito civil a má prática médica pode causar danos ao paciente e gerar ao médico o dever de indenizá-lo. Assim, a responsabilidade civil do médico será a de recompor de alguma forma os danos sofridos pelo paciente, o que normalmente se dá mediante o pagamento em dinheiro. Os pacientes poderão experimentar danos materiais, morais ou estéticos em razão da comprovada má prática médica (artigos $5^{\circ}, \mathrm{V}$ e X da Constituição Federal, artigo $6^{\circ}$, VI do Código de Defesa do Consumidor e artigos 186 e 402 do Código Civil).

Para que se configure o dever de indenizar, é preciso que o profissional tenha agido com a intenção de causar o dano (chamado dolo) ou que, mesmo sem intenção, o profissional tenha causado dano ao paciente por sua atuação imprudente, negligente ou por imperícia (artigo 14, parágrafo $4^{\circ}$. do Código de Defesa do Consumidor e artigo 951 do Código Civil) $)^{2,3}$.

O dever de reparar dos hospitais, das clínicas, dos laboratórios, das operadoras de planos de saúde e dos entes estatais (União, Estados e Municípios) existe, independentemente da intenção de causar lesão (base na Constituição Federal - artigo 37, parágrafo $6^{\circ}$, no Código Civil - artigo 43 ou no Código de Defesa do Consumidor -artigo 14), estes entes são responsáveis pelos atos daqueles que atuam em seu nome, independentemente de terem eles atuado ou não com culpa, tendo a responsabilidade objetiva, bastando demonstrar:

1) o dano causado ao paciente;

2) a relação de causalidade entre a conduta médica e o dano do paciente.

A má prática médica pode surtir efeitos também na esfera penal ${ }^{3}$. Caso a conduta médica seja caracterizada como crime, o profissional arcará com uma pena que pode variar entre a simples imposição de multa até a privação da liberdade ${ }^{3}$. Na esfera penal, apenas o médico pode ser responsabilizado. Isso porque a conduta criminosa depende do agir com vontade, caracterizada pelo dolo ou pela culpa (artigo 18 do Código Penal).

A má prática médica pode causar, em geral, uma lesão à saúde ou à integridade física do paciente, ou ainda sua morte. Dependendo da lesão provocada, a conduta médica poderá ser tipificada como crime de homicídio (artigo 121 do Código Penal) ou como crime de lesão corporal (artigo 129 do Código Penal) ${ }^{2,3}$.

O paciente possui direitos e deveres no que diz respeito à sua saúde, o que inclui a relação com o seu médico e demais profissionais que dela cuidarem. Todo paciente deve: zelar pela própria saúde, tendo uma boa alimentação e hábitos de vida saudáveis; solicitar todos os esclarecimentos sobre sua doença, tratamento, riscos, alternativas e outros que se fizerem necessários; levar para as consultas os exames, radiografias e todo o material que auxilie o diagnóstico; anotar todos os sintomas e as dúvidas; informar corretamente o médico sobre suas condições de saúde; não omitir informações relevantes, como hábitos, medicamentos que utiliza e doenças de que seja, eventualmente, portador; ser objetivo ao relatar o problema e ao responder as questões do médico; responder verdadeiramente todas as questões feitas pelo médico; ficar atento às reações provocadas pelo medicamento e/ou tratamento indicado pelo médico e comunicá-las prontamente, em especial quando diante de uma reação não esperada.

Caso o paciente venha a sofrer algum dano em razão da má prática médica, poderá recorrer ao Conselho de Medicina, órgão profissional responsável por aplicar penalidades aos médicos que cometerem infrações éticas.

A responsabilidade médica em toda a sua amplitude pode ser definida como a obrigação de ordem civil, penal ou administrativa a que estão sujeitos os médicos, no exercício profissional quando de um resultado lesivo ao 
Wild CLDT. Erro médico - o laudo pericial e a decisão judicial.

paciente, por imprudência, imperícia ou negligência. Tal forma de responsabilidade fundamenta-se, como dito acima, no princípio da culpa, em que o agente dá causa a um dano, sem o devido cuidado a que normalmente está obrigado. Procede culposamente quem age sem a necessária precaução, julgando que o dano não se dará; o que implica na seguinte razão: quanto maior a previsibilidade de resultado danoso, maior o grau de culpa ${ }^{3}$.

O erro médico pode ser arguido sob duas formas de responsabilidade: a legal e a moral. A responsabilidade legal é atribuída pelos tribunais, podendo comportar, entre outras, as ações civis, penais e administrativas. A responsabilidade moral é de competência dos Conselhos de Medicina, através de processos ético-disciplinares ${ }^{3}$.

Em nosso, a grande variabilidade na idade dos periciandos faz com que o médico perito tenha que abordar várias áreas da medicina, examinando assuntos da área pediátrica, clínica e geriátrica. A maioria das pericias desse estudo (93\%) se deram de forma indireta, sendo discutido o ato médico e o evento morte.

Cabe salientar que existe uma lacuna de tempo entre a solicitação dos quesitos complementares pelas partes, seu envio até o perito e a resposta aos mesmos. Dessa forma, o número de quesitos complementares encontrados nesse estudo, provavelmente é subestimado. Da mesma forma, tal evento pode contribuir para o retardo da decisão judicial.

\section{CONCLUSÃO}

Erro médico é um assunto complexo, que abrange várias facetas da relação médico-paciente. Sua caracterização necessita de abordagem ampla para poder diferenciar o erro do caso fortuito ou de força maior, entre eles as complicações da doença ou do procedimento. $\mathrm{O}$ perito médico judicial depara-se com a dificuldade de analisar o profissional, o ato profissional, a ausência de dolo, a existência de dano, a relação causal entre o ato e o dano e os deveres do doente. Não cabe ao perito formar juízo e fazer julgamentos, essa é a função do magistrado. O perito necessita elaborar um laudo no qual se esclareçam os pontos controversos: a culpa, o nexo causal, e a existência de dano.

A maioria das ações processuais levantadas ainda não foi julgada, após 2 anos de emitido o laudo pericial. Isto pode ser explicado pela complexidade do assunto, e pelo fato de as partes contra-argumentarem todas as etapas do processo, inclusive com a solicitação de quesitos complementares para o médico perito, levando à morosidade processual.

O laudo pericial foi acatado pelo juiz em $85 \%$ (11 casos) das decisões judiciais, mostrando que, na grande maioria dos casos, é ele que norteia o julgamento.

\title{
AGRADECIMENTOS
}

Ao Imesc pela liberação dos dados.

Ao Centro de Estudos Darcy Vargas pelo financiamento da pesquisa.

Wild CLDT. Malpractice - the expert report and the judicial decision. Saúde, Ética \& Justiça. 2014;19(1);21-25.

\begin{abstract}
Any failure that occurs during the performance of health care that causes some kind of harm to a patient is considered as "malpractice". The objective of this study was to evaluate judicial expertise in medical malpractice and correlate the expert report and its influence on judicial decision. A retrospective analysis was done of 30 expert reports carried out at the Institute of Social Medicine and Criminology of the State of São Paulo (IMESC) in the period JanuaryApril 2010. The analysis was performed in January 2013. The expert report was able to determine a causal correlation between the medical care and the damage to patients in 8 cases, in which irregularities were detected in the medical act (malpractice). Thirteen cases had been tried in the 1st instance, 10 having been dismissed. The expert report was accepted by the judge in $85 \%$ (11 cases) of judgments, showing that, in most cases, it is the one that guides the judgment.
\end{abstract}

KEYWORDS: Perícia médica (judicial expertise); Erro médico (malpractice medical error); Decisão judicial (judicial decision).

\section{REFERÊNCIAS}

1. Idec - Instituto Brasileiro de Defesa do Consumidor [Internet]. Guia sobre erro médico - orientações ao consumidor. São Paulo, SP; 2006 dez.

2. Maria Helena Diniz. O Estado Atual do Biodireito. $9^{\text {a }}$ Ed.
2014. Ed Saraiva.

3. Fernandes JNL. Erro Médico e Responsabilidade Civil. [Monografia]. São Paulo: Universidade Presbiteriana Mackenzie; 2010.

Recebido em: 09/06/2014

Aprovado em: 25/06/2014 